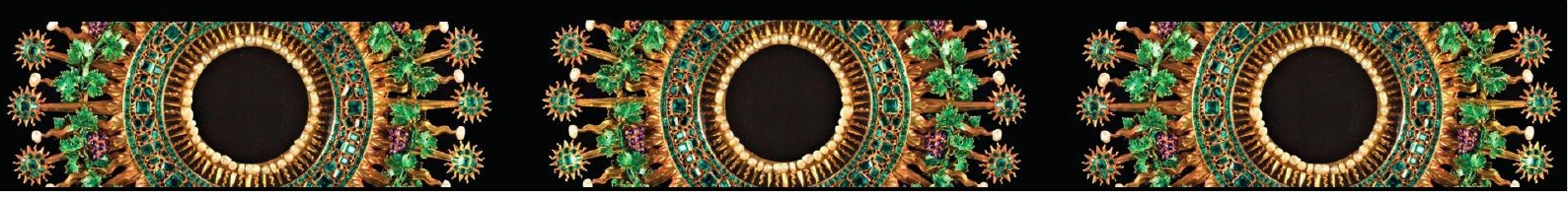

Artículo de investigación E15A10 Proyecto historiográfico "Nariño el Contador, el Precursor-Libertador:

La Ilustración, la Independencia” * Escuela Militar de Cadetes José María Córdova

Universidad Libre de Colombia * Recibido: 07.04.2019 * Aprobado versión final 14.06.2019

JEL: H83, M41, N01, N96 * pp. 59-83 * doi:10.33571/teuken.v10n15a2

\title{
Más allá del enigma del medallón. Un descubrimiento histórico para reescribir la historia de Magdalena Ortega y Antonio Nariño.
}

\author{
Beyond the enigma of the medallion. \\ A historical discovery to rewrite the story \\ of Magdalena Ortega and Antonio Nariño.
}

\section{Jesús Alberto Suárez Pineda COLOMBIA}

Resumen: Aunque la investigación que sustenta este trabajo se centra en la faceta de contador y custodio de recursos públicos de Antonio Nariño, este artículo es una aportación a la polémica histórica sobre la supuesta infidelidad de Magdalena Ortega de Nariño que suscitó la publicación del libro El enigma del medallón de Carmen Ortega Ricaurte (2000). La discusión de la evidencia utiliza el método iconográfico, aplicado en este caso particular, al estudio de dos grabados originales que aparecen pegados en un folleto impreso de 34 páginas, firmado de puño y letra de Antonio Nariño. El trabajo contó con la ayuda de expertos de la talla de Enrique Santos Molano, la mayor autoridad en Nariño en la actualidad.

Palabras clave: antonio nariño y álvarez; defensa del general nariño de 1823; historia de la contabilidad; iconografía de nariño; litografía.

Abstract: Although the research supporting this work presents a global overview of Antonio Nariño as an accountant and as a custodian of public resources, the article is a contribution to the historical controversy over the supposed infidelity of Nariño's wife, Magdalena Ortega that generated the publication of the book "El enigma del medallón" (The enigma of the medallion), by Carmen Ortega Ricaurte (2000). The discussion of the evidence uses the method of iconography, i.e. treaty or description of images, portraits, statues, etc. For our case, we studied two original engravings that appeared stuck in a printed booklet of 34 pages, signed by Antonio Nariño in his own hand, with the help of leading experts such as Enrique Santos Molano, the highest authority in Nariño today. The results of the research also present new facets of the Precursor of Colombian Independence in terms of his accounting work in the management of public resources.

Keywords: accounting history; antonio nariño y álvarez; general nariño's defense of 1823; lithography; nariño's iconography.

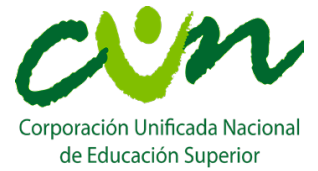
de Educación Superior

Jesús Alberto Suárez es Doctor en Estudios Políticos de la Universidad Externado de Colombia y Licenciado en Filología y Humanidades de la Universidad Nacional de Colombia. Miembro de Número de la Academia de Historia Militar. Ha sido editor de la revista "José María Córdoba" de la Escuela Militar de Cadetes y autor y coautor de varios libros y artículos sobre teoría e historia de la Contabilidad. Actualmente es docente investigador de la Corporación Unificada Nacional de Educación Superior y Director de la Biblioteca de Pensamiento Vivo Anthos Contable.

Contacto: jesus_suarez@cun.edu.co https://orcid.org/0000-0002-1155-3175. 
Além do enigma do medalhão.

Uma descoberta histórica para reescrever

a história de Magdalena Ortega e Antônio Nariño

Resumo: Ainda que a pesquisa que sustenta este artigo se concentra em dom Antônio Nariño e na sua qualidade de contador e custódio de recursos públicos, este artigo é uma contribuição à polêmica histórica sobre a suposta infidelidade de sua esposa dona Magdalena Ortega, segundo a publicação do livro O enigma do medalhão de Carmen Ortega Ricaurte (2000). A discussão da evidência utiliza o método iconográfico, aplicado neste caso, ao estudo de duas gravuras originais que aparecem coladas em um folheto impresso de 34 páginas, firmado com o punho e a letra de Antônio Nariño. O trabalho contou com a colaboração de expertos como o mestre Enrique Santos Molano, a maior autoridade em Nariño agora.

Palavras-chave: antônio nariño y álvarez; defesa do general nariño de 1823; história da contabilidade; iconografia de nariño; litografia.

\section{Introducción}

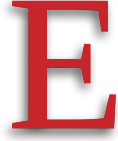

ste trabajo no pretende discutir específicamente la defensa de Magdalena Ortega de Nariño, esposa del Precursor de la Independencia de Colombia, Antonio Nariño y Álvarez, por cuenta de la supuesta infidelidad que se le atribuye en libro El enigma del medallón de Carmen Ortega Ricaurte (2000), en el sentido de que Nariño no era el padre de Isabel y Mercedes, sus dos hijas menores, sino que serían hijas biológicas del también prócer republicano Jorge Tadeo Lozano y González, vizconde de Pastrana e hijo menor del Marqués de San Jorge.

Figura 1. Portada del libro El enigma del Medallón de Carmen Ortega Ricaurte (2000), que representa un cuadro atribuido a Joaquín Gutiérrez.

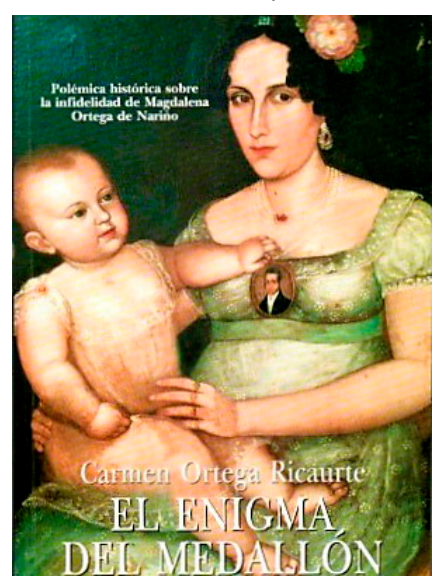

No obstante, sí se pretende cuestionar el análisis historiográfico que sustenta esa hipótesis y aportar nuevas luces sobre la figura de doña Magdalena Ortega de Nariñoy el aporte del Precursor en el campo contable. Para actualizar la discusión, debe decirse que la polémica se originó en el análisis que la profesora Carmen Ortega hizo de un cuadro atribuido a Joaquín Gutiérrez (fig. 1), que presenta una dama con una bebé que acaricia un medallón o camafeo sobre el pecho de su madre, ilustrado con la efigie de un hombre elegantemente vestido. La investigación de Ortega concluye que la dama es doña María Magdalena Ortega y Mesa, esposa 
del prócer republicano Antonio Nariño y Álvarez, y que el hombre pintado en el medallón es don Jorge Tadeo Lozano, lo que la hace concluir que la bebé sería su hija, como producto de una presunta infidelidad de la dama, consecuente con el desamparo en que quedó al ser encarcelado su esposo por los españoles.

La acalorada discusión que suscitó este libro entre los académicos concluye que se trataba de una acusación sin fundamento histórico (Velandia, 1995; Restrepo, 1954) ni iconográfico (Osorio, 2001), y complementada por el mismo autor con nuevas pruebas (Osorio, 2003).

Desvanecida la acusación de adulterio de doña Magdalena, este artículo discute un nuevo hallazgo que ratifica la integridad de esta heroína nacional de la Independencia, digna y sufrida esposa del PrecursorLibertador Antonio Nariño y Álvarez, quien con decisión, se dirigió ante el rey de España como una «americana» para interceder por su marido, caído en desgracia por la causa independentista.

El documento presenta algunas evidencias que demuestran la idoneidad de Antonio Nariño en su oficio de contador y tesorero de diezmos en tiempos coloniales, y destaca su prestancia moral y su carácter de revolucionario ilustrado.

\section{Metodología}

La búsqueda de evidencia utiliza el método iconográfico, o interpretación y análisis de imágenes, retratos, estatuas, etc., en sus fuentes clásicas e imaginarios de la época (Allo Manero, 2015, t. 1: 12-21).

Para este caso particular, se estudiaron dos grabados originales que aparecieron pegados en un folleto (Nariño, 1823a), que se conserva en la Biblioteca "Tomás Rueda Vargas" de la Escuela Militar de Cadetes en Bogotá, Colombia, y que son inéditos en la iconografía de Nariño. Su interpretación y análisis nos llevó al descubrimiento del rostro de doña Magdalena Ortega, esposa del Precursor-Libertador, avalado por Enrique Santos Molano, la mayor autoridad en Nariño en la actualidad. Allí también aparece la firma de puño y letra de Nariño con tinta roja (rúbrica, en su sentido etimológico), y que puede apreciarse mejor en el facsímil que acompaña la edición abreviada de la edición crítica del informe de la investigación que soporta este artículo (Suárez, Franco, Molina, et al., 2018; Suárez y Molina, 2019). Adicionalmente, el trabajo se soporta en la revisión de literatura especializada sobre la figura histórica del Precursor y el análisis de su contenido, orientado por las categorías de ejercicio contable público y biografía política. 


\section{Discusión}

Antonio Amador José Nariño y Álvarez nació en Santa Fe de Bogotá el 9 de abril de 1765, en el seno de una influyente familia de abolengo, y murió en Villa de Leyva (Boyacá, Colombia), en medio de insidias políticas, a la edad de cincuenta y ocho años, el 13 de diciembre de 1823.

Se sabe que el doctor José Celestino Mutis atendió el parto de Antonio Nariño, nacido en pésimas condiciones de salud, según el dictamen del médico. Traía el pecho mal conformado y predispuesto a enfermedades como la tisis pulmonar y la hidropesía de pecho o del pericardio, pero estaba en manos de unos padres que lo cuidaron con especial esmero. Así, Nariño debió la vida a la ciencia del Sabio Mutis, quien luego sería su maestro.

Podemos identificar tres etapas en la vida de Nariño: la juventud (17651794), la de un revolucionario (1794-1820) y la de un hombre de Estado (1820-1823). De la segunda etapa se conoce un retrato hablado de Nariño.

En la Iconografía de Nariño, que realizaron Guillermo Hernández de Alba y Fernando Restrepo Uribe, se cita su retrato hablado, en papeles curialescos de la Real Audiencia de Santa Fe: "Buen cuerpo, blanco, algunas pecas en la cara, ojo cuencudo o saltado (véase fig. 3), pelo rubio claro, boca pequeña (véanse fig. 3 y 4) labios gruesos y belfo (véanse fig. 6 y 7), habla suave, tono bajo y algo balbuceante, de 34 años" (Hernández y Uribe, 1983: 7-8, 45). Así lo describe la policía del Estado colonial del Nuevo Reino de Granada, el 18 de julio de 1797, fecha en que se ordena su nueva captura. El reo en realidad tenía treinta y dos años.

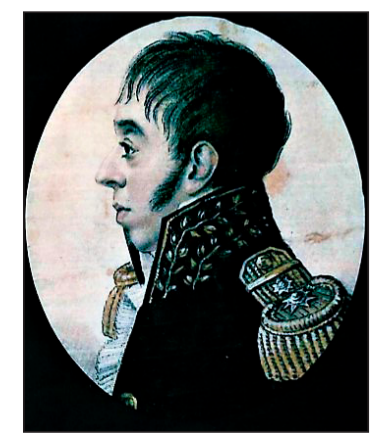

Figura 2. Nariño tomado del natural. Plancha de mezzo-tinto. París, 1820. Grabador Bouchard. $6.5 \times 5 \mathrm{~cm}$. P. (Hernández y Restrepo, 1983: fig. 58).

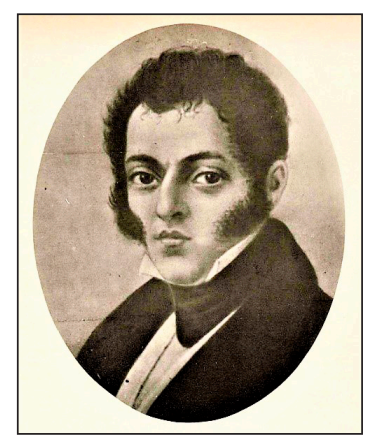

Figura 3. Retrato de Antonio Nariño de autor anónimo de principios del siglo XIX. Atención de la familia Sáiz Concha. Bogotá. Iconografía de Nariño, (Hernández y Restrepo, 1983: fig. 18). 


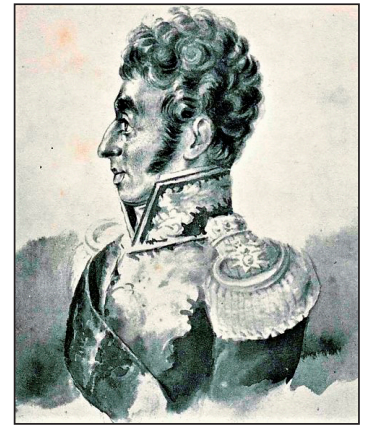

Figura 4. Antonio Nariño. Aguada por José Gabriel Tatis Ahumada (1813-1884). (Hernández y Restrepo, 1983: fig. 62).

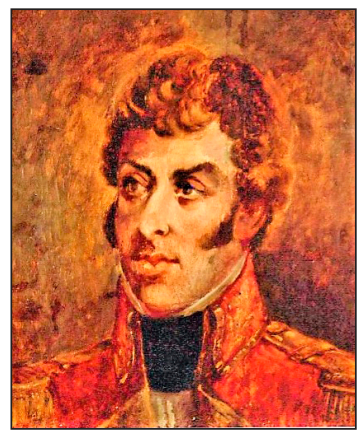

Figura 6. Antonio Nariño por José María Espinosa (1796-1883). Óleo sobre tela $60 \times 54 \mathrm{~cm}$. Propiedad de monseñor Emilio de Brigard Ortiz, tataranieto de Nariño. Bogotá. (Hernández \& Restrepo, 1983: fig. 69).

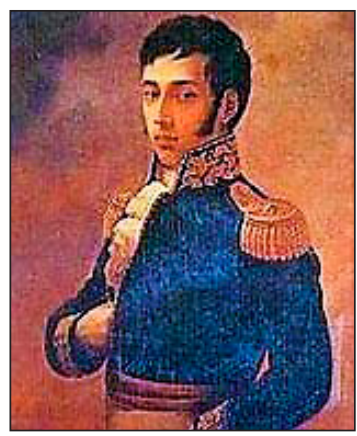

Figura 8. Antonio Nariño por Ramón Torres Méndez (1809-1885). Óleo sobre tela. 100x82 cm. Donación de la familia Vargas Nariño. Jockey Club. Bogotá. (Hernández y Restrepo, 1983: fig. 72).

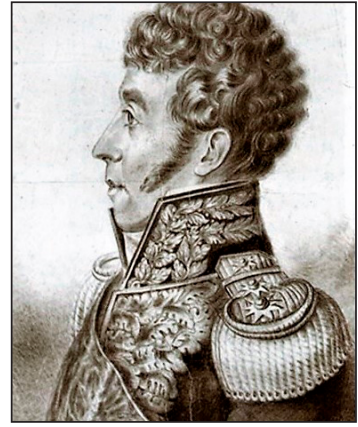

Figura 5. Antonio Nariño. Grafito sobre papel, 69 x 48 cm. por José María Espinosa (17961883). Ca. 1825. (Hernández \& Restrepo, 1983: fig. 64).

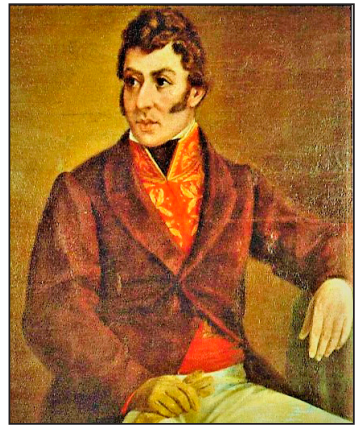

Figura 7. Antonio Nariño por José María Espinosa (1796-1883). Óleo sobre tela $121 \times 80 \mathrm{~cm}$. Donación de sus bisnietas Carolina y María Luisa Ibáñez-Nariño Manrique. Museo 20 de Julio. Bogotá. (Hernández \& Restrepo, 1983: fig. 70).

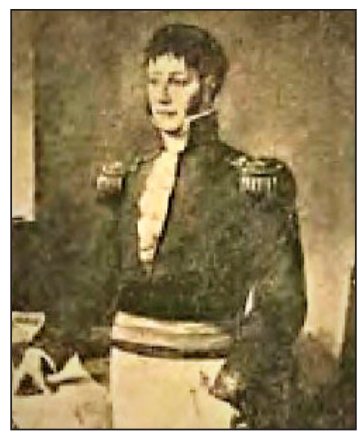

Figura 9. Antonio Nariño por Ramón Torres Méndez (1809-1885). Óleo sobre tela. 250×120 $\mathrm{cm}$. Colección Museo de la Independencia Casa del Florero. Reg. 515. (Hernández \& Restrepo, 1983: fig. 79). 
Cabe preguntarnos cuál pueda ser considerado el retrato más fiel de don Antonio Nariño, cuya fisonomía ha quedado definida con diferentes rasgos en la iconografía de su época (fig. 2 y 3), por pintores como José María Espinosa (fig. 5-7), abanderado de Nariño, José Gabriel Tatis (fig. 4) y Ramón Torres Méndez (fig. 8 y 9).

Hasta aquí, la iconografía conocida de Nariño, la cual tendrá especial importancia para dilucidar la incógnita central de este artículo. Sin embargo hay facetas de este gran hombre que empiezan a salir a la luz gracias a la investigación y que deben ser destacadas.

\section{Nariño: un hombre de cuentas claras}

El campo contable desempeñó un papel fundamental en la época de la Independencia, aunque es poco conocido: fue el origen de la contabilidad pública para la organización de las cuentas de la naciente República, azotada por el flagelo de la corrupción de algunos funcionarios. Luego de la Batalla de Boyacá (7 de agosto de 1819), que frustró el intento de reconquista española y le dio a Colombia la libertad, el país se encontraba en una grave crisis fiscal. La empresa emancipadora había sido costosa y las arcas nacionales estaban exhaustas. Por eso, se recurrió a empréstitos, contratados especialmente con Inglaterra, para superar la penuria económica de la República, pues la Hacienda Pública se encontraba en un estado crítico, al borde del colapso.

El sombrío panorama de quiebra fiscal y de corrupción era insostenible y por ello el régimen de Santander (vicepresidente con funciones presidenciales) se vio abocado a tomar medidas drásticas, como la promulgación de la Ley principal del 23 de octubre de 1819 contra los empleados de Hacienda, que contemplaba la pena de muerte para los funcionarios defraudadores del Fisco Nacional. Organizada la Campaña del Perú, en 1824, Bolívar se percató de que esa nación también vivía una crisis fiscal similar a la de la Nueva Granada de 1819, agravada por el saqueo descarado contra el erario, de modo que dictó un decreto, que ratificaba la ley anticorrupción promulgada por Santander.

Muchos años atrás, en la capital colombiana, Nariño se había formado como autodidacta' en el seno de una familia de contadores, cargo propio de la nobleza y del clero, que eran las clases privilegiadas que conformaban la élite del Estado colonial. Ávido lector de múltiples temas 
jurídicos, históricos, filosóficos, políticos y culturales, Nariño no fue solo el precursor del gran resquebrajamiento colonial del imperio español que significó la Independencia de Colombia; también fue el precursor del periodismo político y de la asistencia social en la época granadina, e incluso el precursor de la oratoria parlamentaria en los primeros días de la República, como puede constatarse en la célebre "Defensa del General Nariño ante el Senado en 1823", maravillosa pieza de la oratoria parlamentaria y de contabilidad forense, de cuyo texto presentamos (anexo 1) el fragmento referido al cargo malversación de fondos del Tesoro de Diezmos. "Los Diezmos constituían un cuantioso fondo de propiedad de la curia de Santafé, cuyos rendimientos provenían exclusivamente de los intereses que pagaban los ciudadanos a quienes se les otorgaba algún crédito con fondos provenientes del Tesoro de Diezmos" (Santos, 2013: 50).

En su Defensa, Nariño demuestra con pruebas incontestables su inocencia contra las tres acusaciones de sus enemigos políticos, que buscaban impedir su nombramiento como senador, a saber: malversación de fondos cuando era tesorero de diezmos en 1794; haberse entregado al enemigo voluntariamente en la Campaña del Sur (Pasto, 1814), y no cumplir con el tiempo de residencia requerido para ser senador de la República, según la Constitución de 1821. A lo largo del documento se aprecia la sorprendente meticulosidad con que Nariño desmiente los supuestos cargos que se le habían imputado, 29 años después de ocurridos los hechos; reconstruye las cuentas que estaban a su cargo de contador tesorero y argumenta en favor de su honra. Sorprende aún más, que sin ninguna formación académica que conste en documento, Nariño tenga la pericia para el manejo de las cuentas, domine la técnica de cargo y data y pueda, además, argumentar con referentes jurídicos, históricos y filosóficos, su Defensa ante el Senado de Colombia.

La contabilidad señorial de los reinos españoles de América se llevaba por el sistema de control de cargo y data, y luego de la Independencia no hubo disolución de los lazos coloniales en las prácticas contables, pues continuó el sistema que se había instituido en las Partidas de Alfonso X el Sabio, para el control de las cuentas de cajas reales y administración de diezmos. Este sistema de control se conservó igualmente en las prácticas comerciales de la administración colonial española e incluso en el manejo de los asuntos públicos del Estado colombiano hasta bien entrado el siglo XX.

El proceso de Diezmos tenía una estructura administrativa muy particular (fig. 10). Los diezmeros recaudaban directamente el impuesto eclesiástico; luego entregaban los fondos, con sus respectivos soportes, al enterador, quien a su vez los entregaba al tesorero mayor, para su custodia y posterior entrega a los destinatarios: 7/9 a los eclesiásticos y los 2/9 restantes, a las cajas reales de la Corona. 
Figura 10. Estructura administrativa de Diezmos

Virreinato de la Nueva Granada, 1780-1809.

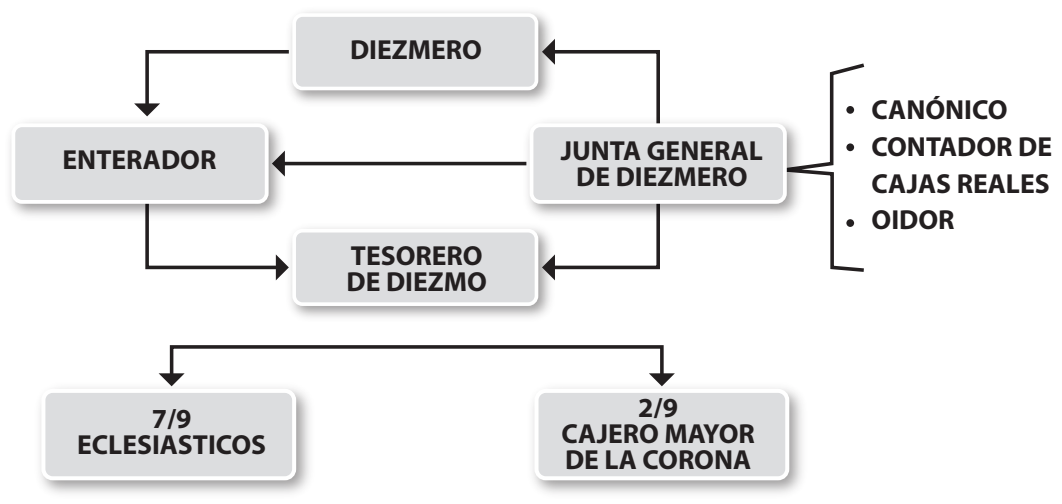

Fuente: Franco Ruiz y Suárez Pineda, en Suárez, Franco, Molina, Acosta y Alonso, 2018: 127.

Las cuentas se ordenaban por orden cronológico, y no por su naturaleza. El cargo representaba las cantidades que el funcionario real había recibido, y estaba conformado por partidas que en una cuenta componían el adeudo u obligación de pagar y que debía dar salida; la data indicaba las partidas que componían el descargo de lo recibido. En este sentido, se entendía por datar la acción de anotar en las cuentas partidas de data, es decir, abonar o acreditar. Un cargo representaba siempre una entrada de tesorería, y una data, una salida. El documento en que constaba el hecho de dar por concluida una cuenta o la totalidad de las cuentas, se llamaba finiquito, una suerte de paz y salvo del tesorero. El control del tesorero se hacía por medio de las declaraciones juradas que éste hacía en los libros de cargo y data, las cuales debían ser enviadas a la Contaduría del Consejo de Indias.

La función de tesorero conllevaba la de contador, pues el manejo de los fondos reales era una responsabilidad personal intransferible, que se otorgaba en atención a las condiciones de reconocida honorabilidad del candidato a investirse. Nariño desempeñó con especial decoro las funciones del cargo, hasta cuando fue arrestado, acusado de alta traición a la Corona, por su publicación de "Los Derechos del Hombre y el Ciudadano", que había traducido del francés. La lectura del anexo 1 podrá ilustrar no solo el nivel de precisión de las cuentas sino también la lógica del sistema contable que Nariño administró y que conocía al máximo detalle.

\section{Más allá del enigma}

Retomando la discusión inicial, respecto de las figuras de doña Magdalena Ortega y don Antonio Nariño, debe centrarse la atención ahora, en el 
misterio que encierran dos grabados que aparecen pegados en la primera página en blanco (fig. 11), siguiente a la portada de un folleto de la Defensa de Nariño ante el Senado, cuya edición impresa de 34 páginas (1823a) se conserva en la Biblioteca Tomás Rueda Vargas, sede de la Academia de Historia Militar, ubicada en el campus universitario de la Escuela Militar de Cadetes "General José María Córdova", en Bogotá.

Figura 11. Litografías pegadas en una edición impresa de la Defensa del general Nariño (Nariño, 1823a).

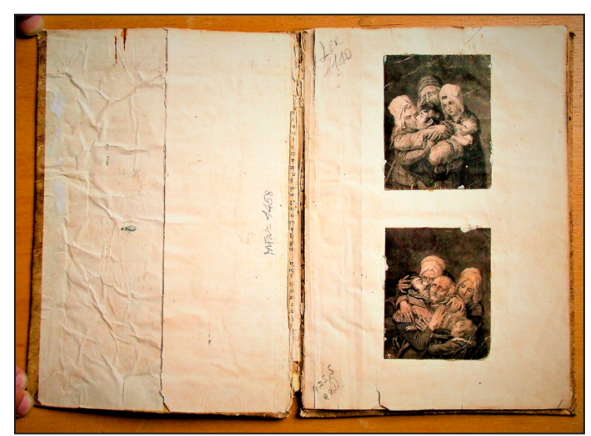

¿A quién perteneció el ejemplar hallado en la Biblioteca Tomás Rueda Vargas? ¿Quiénes son las personas que aparecen en los cuadros? ¿En qué contexto aparecen las personas allí representadas? ¿Quién es el artista? ¿Quién el grabador? Responder estos interrogantes fue una tarea bastante difícil. No sabemos nada seguro sobre la procedencia del folleto ni cómo fue a parar a una biblioteca castrense. Es posible que haya venido a través del general Wenceslao Ibáñez Nariño, hijo de Mercedes Nariño, pero curiosamente estos grabados no aparecen en la versión impresa de 89 páginas (Nariño, 1823b) que reposa en la Biblioteca Nacional de Colombia. La escena representaría un momento muy doloroso en la vida de los personajes. ¿De la vida de Nariño? Los hechos no concuerdan. Lo que sí podemos afirmar con certeza es que el joven de unos 26 años que besa a la señora corresponde a la fisonomía de los retratos que conocemos de Nariño (especialmente la figura 2). También podemos determinar que los retratos, sin duda, fueron pegados con posteridad a 1823, año de su publicación por Bruno Espinosa de los Monteros, impresor del Gobierno. Los grabados en papel, inéditos hasta ahora (véase fig. 11), presumiblemente fueron realizados en la Litografía de Bogotá, con base en un cuadro atribuido a Joaquín Gutiérrez (s. XVIII), amigo de Nariño.

En un principio pensamos que la persona a quien Nariño besa era su esposa Magdalena Ortega y Mesa, pero el maestro Enrique Santos hizo caer en la cuenta de que no podía ser Magdalena, pues la dama del grabado le lleva por lo menos quince años, y Magdalena (julio de 1762) era mayor que su esposo (abril de 1765) solo menos de tres años. Después de examinar minuciosamente los dos cuadros, Santos Molano (2017: 3740) llegó a la conclusión de que ambos representan, no escenas aflictivas de la vida de Nariño, sino escenas de una obra de teatro. 
En efecto, don Antonio Nariño mantuvo estrechos vínculos con el teatro. La tertulia que fundó en su casa (1789) con el nombre de Arcano Sublime de la Filantropía, no solo era una sociedad secreta de ideas para discutir temas científicos, políticos y económicos con personajes que influyeron notablemente en el proceso de la Independencia de Colombia (Suárez, Franco, Acosta y Alonso, 2017: 73-78), sino que también fue escenario para representar diversas piezas de teatro y sainetes con su familia. "En la biblioteca de Nariño se hallaron obras de Plauto y Terencio, así como tres tomos de las comedias de Molière" (Reyes, 2000: 18). Cuenta José Vicente Ricaurte en su Historia crítica del teatro en Bogotá (1927) que poco antes de ser arrestado el Precursor, en su casa se había presentado un sainete con la participación de dos de sus hijos.

Ahora bien, ¿cuál es la obra que representan, en qué año y en dónde? La respuesta la encuentra Santos Molano en un artículo publicado en la edición 42 del Papel Periódico de la Ciudad de Santafé de Bogotá, del viernes 2 de diciembre de 1791 (t. 2, pp. 345-349) que informa que el pasado 6 de noviembre se había estrenado la tragicomedia El Delincuente honrado, de Gaspar Melchor de Jovellanos, en obsequio del virrey Ezpeleta. La obra estaba precedida de una loa, compuesta por don Manuel del Socorro Rodríguez, a quien se atribuye la adaptación de la obra representada (fig. 12 y 13$)$.

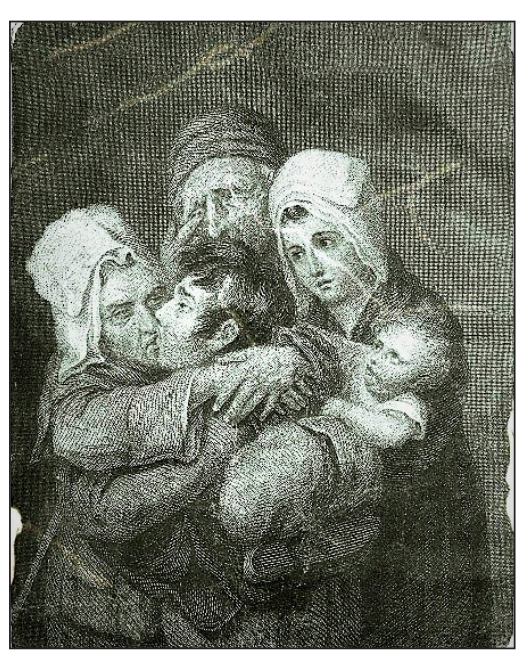

Figura 12. Nariño en función teatral, representando una adaptación hecha por Manuel del Socorro Rodríguez de El delincuente honrado (acto II, escena $\left.5^{a}\right)$, de Jovellanos, c. 1791. Litografía en papel $(8 \times 6 \mathrm{~cm})$.

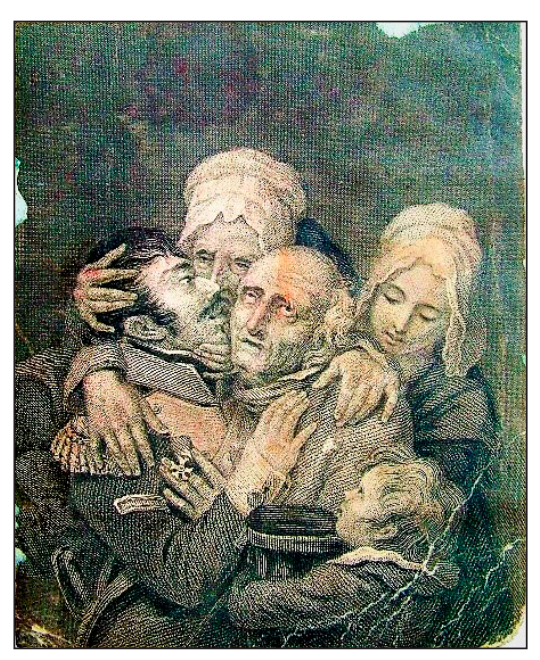

Figura 13. Nariño en función teatral. El delincuente honrado (acto $\mathrm{V}$, escena $5^{\mathrm{a}}$ ) de Jovellanos, c. 1791. Litografía en papel $(8 \times 6 \mathrm{~cm}$.). 
Por consiguiente, aduce Santos Molano, lo más seguro es que la bella y joven mujer que sostiene al niño, de seis o siete meses de nacido Antonio Nariño y Ortega, nacido en junio de 1791- sea su propia madre, Magdalena Ortega (fig. 12), en el personaje de la obra que ella representa. En la figura 13, aparece Gregorio, de seis años, primer hijo del matrimonio Nariño-Ortega, nacido en marzo de 1786. Es posible que la señora a quien besa Nariño, sea Rafaela Isazi de Lozano, conocida como La Jerezana, oriunda de Jerez de la Frontera, España. Era esposa de José María Lozano, segundo marqués de San Jorge. ${ }^{2}$

Los actores adultos de los dos grabados son los mismos, aunque representan dos escenas antitéticas de tristeza y alegría que se rigen por una retórica de las lágrimas, centrada en el problema de que trata la obra, en la emoción de contrición que produce contemplar los personajes ante los apremios del infortunio, según las ideas estético-dramáticas de su época, descubriendo en ellos la emoción del sollozo y de los "iay de mí!"

«Si las lágrimas son efecto de la sensibilidad del corazón, ¡desdichado de aquel que no es capaz de derramarlas!», le amonesta Torcuato, a su fiel amigo Anselmo, en el primer acto de la pieza teatral (I.iii). Derramar lágrimas, en efecto, es señal de sentimiento y sensibilidad, al igual que de compasión y piedad, que, en términos de las virtudes judiciales, exhortan a la clemencia y al perdón.

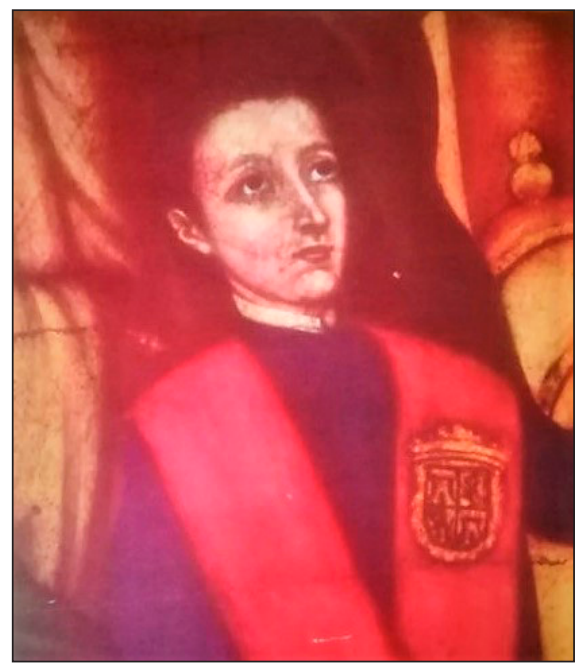

Figura 14. Don Manuel Bernardo Álvarez del Casal (1743-1816), tío materno de Nariño. Colegial de San Bartolomé, Contador Mayor del Tribunal de Cuentas de Santafé (1803-1810), firmó el Acta de Independencia el 20 de julio de 1810; como presidente del Colegio Electoral (1813) declaró el 5 de julio, la absoluta separación de la monarquía española. Fue fusilado por orden de Pablo Morillo en la Plazuela de San Francisco de Bogotá en 1816, cuando contaba 73 años.

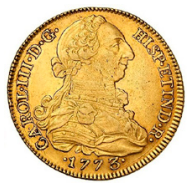

2 Santos Molano aclara que "las dos marquesas anteriores fueron María Tadea Manrique, primera esposa y Magdalena Cabrera, segunda esposa del primer marqués de San Jorge, don Jorge Miguel Lozano de Peralta" (Suárez, Franco, Acosta y Alonso, 2017: 36, n. 3). 
La escenificación y teatralidad del grabado muestra, en primer plano, a un anciano de rostro circunspecto (fig. 13) que guarda gran parecido con don Manuel Bernardo Álvarez ${ }^{3}$ (fig. 14).

Ahora, la pregunta clave: ¿Qué relación tienen las escenas pintadas en los grabados con El delincuente honrado de Jovellanos? Según el maestro Enrique Santos Molano, los personajes representan dos escenas del drama de Gaspar Melchor de Jovellanos. En realidad se trata de una obra derivada, vale decir, de una adaptación teatral que hiciera el periodista cubano Manuel del Socorro Rodríguez, ${ }^{4}$ que había llegado a Santafé hacia 1790 en compañía y bajo la protección del virrey Ezpeleta.

Las dos pinturas de Gutiérrez muestran las escenas del comienzo (acto II, escena $5^{\mathrm{a}}$ ) y del final (acto $\mathrm{V}$, escena $5^{\mathrm{a}}$ ) del Delincuente honrado de Jovellanos. Al comenzar la última escena de la obra, Laura se dirige así a Torcuato: «iAh, querido esposo...!». Y él responde corriendo a abrazarla: «iAh, Laura mía...!» (V.vii). En esa misma escena, Torcuato se dirige así a don Simón, su suegro: «iPadre mío...!». Simón, abrazando a Torcuato, su yerno, le reprocha: «Buen susto nos has dado, hijo; Dios te lo perdone...» (V.vii). El anciano es representado por don Manuel Bernardo Álvarez, tío materno de Nariño (fig. 13), debidamente maquillado. Los tiempos cambian. Doña Laura y su doncella Eugenia observan cómo, cuando el drama está en el clímax, un giro inesperado conduce la tragedia a un final feliz.

En las circunstancias descritas de efervescencia social que vivieron los santafereños en 1791, fue que se representó por primera vez El delincuente honrado, ${ }^{5}$ en el primer teatro que tuvo Bogotá, que estaba en el mismo lugar que hoy ocupa el Teatro Colón.

3 La reconquista española de la Nueva Granada propició el asesinato de casi todos los líderes de la Revolución. Luego del fusilamiento de don Manuel Bernardo Álvarez del Casal, el "Pacificador" Morillo obligó a las hijas del veterano patriota a caminar descalzas hasta la ciudad de Zipaquirá para que sufrieran el escarnio público.

4 Padre de Periodismo colombiano, Rodríguez fue designado por el virrey Ezpeleta para ocupar el cargo de Bibliotecario Real, con un sueldo de 280 pesos anuales. Vivió siempre y hasta su muerte, en un cuarto contiguo a la biblioteca, cumpliendo bien y fielmente los deberes de su encargo, consagrándose con solícito interés a la difusión de las luces.

5 Un amigo de Nariño, Tomás Ramírez, gran entusiasta del teatro, fundó y regentó "el Coliseo", primer teatro de la capital colombiana y tuvo el mérito de ser el primero en representar en Santafé El delincuente honrado, de Baltasar Melchor de Jovellanos. Este drama español fue puesto en escena varias veces en Santafé en la primera mitad del siglo XIX, entre 1823 y 1828 (Lamus, 2010: 481). Sobre las ruinas del "Coliseo Ramírez" se levantó el majestuoso Teatro Colón, en el barrio de La Candelaria de la capital colombiana. 
El tiempo del drama, en efecto, escasamente transcurre en el lapso de veinticuatro horas: el primer acto empieza a las 7:00 a.m. (I.ii) y el quinto a las 11:00 a.m. del día siguiente (V.i). Según lo publicó el bibliotecario Manuel del Socorro Rodríguez, la obra derivada de Jovellanos se estrenó solemnemente la noche del 6 de noviembre de 1791 en obsequio al virrey José de Ezpeleta y de su esposa doña María de la Paz Enrile, con motivo de la inauguración del Cuartel de San Agustín, que albergaba la guarda del Virrey.

He aquí la descripción de las dos escenas de la obra derivada que corresponden con la escenografía representada en los grabados:

La primera (fig. 12) en que Torcuato (Antonio Nariño) le confiesa a su mujer, doña Laura (¿Rafaela Isazi?) el crimen del que es culpable, y ella, aterrada, lo abraza mientras él le da en la boca el beso del adiós. Llorando a moco tendido observa la tragedia de su hija don Simón (¿Manuel Bernardo Álvarez?), suegro de Torcuato, y con rostro compungido Eugenia (Magdalena Ortega), doncella de doña Laura, sostiene en sus brazos al hijo pequeño (seis meses) de doña Laura y de Torcuato. La segunda (fig. 13) retrata la escena en que Torcuato, con gesto conturbado por la emoción, se entera de que, después de casi seis años en espera de la ejecución de la pena de muerte a la que ha sido condenado por matar en un duelo al primer marido de su esposa, recibe la noticia de que el rey le ha perdonado la vida al comprobar que Torcuato no fue quien provocó el duelo, y es abrazado por su padre, el corregidor don Justo de Lara, quien le había dictado la condena sin saber que Torcuato era su hijo. Observan doña Laura y Eugenia, y el hijo de Torcuato y de Laura, que tiene ya seis años. La trama de El delincuente honrado transcurre en el Alcázar de Segovia. Los actores infantiles son Antonio Nariño y Ortega (de seis meses, $n$. julio de 1791) y Gregorio Nariño y Ortega (de seis años, n. marzo de 1786). (Santos Molano, en Suárez, Franco, Acosta y Alonso, 2017: 39).

El genial descubrimiento de Santos Molano es muy relevante para comprender el carácter de dramatis persona de un Nariño siempre sorprendente, como es la faceta de participar como actor en obras de teatro para regocijo de los espectadores de la capital virreinal del Nuevo Reino de Granada.

Existen grandes diferencias entre la consabida adaptación de don Manuel del Socorro Rodríguez y el drama original de Jovellanos El delincuente honrado, obra de carácter literario, experimental e innovador en España, que es considerada como el primer ejemplo de lo que se ha dado en llamar comedia lacrimosa, cuya trama es la siguiente: Torcuato, joven caballero, mata por honor en un duelo secreto al infame esposo de Laura, la señora con quien contrae matrimonio, con la anuencia de don Simón, padre de 
Laura. La causa del duelo no fue la rivalidad amorosa, sino la insolencia del aristócrata muerto, mal sujeto, libertino, jugador y pendenciero. Obligado a confesar su crimen, para salvar a su leal amigo Anselmo, Laura lo perdona, al conocer las circunstancias del crimen y trata de salvarlo. Convicto y confeso, es confinado en las mazmorras del alcázar de Segovia, y condenado a muerte por don Justo, un juez riguroso que resultó ser su propio padre. En el último momento llega el perdón real, conseguido por Anselmo, volviendo la felicidad a una familia atormentada por tantos sinsabores.

Por lo demás, en ninguna escena de la obra original se menciona que los recién casados, Laura y Torcuato, hayan tenido un hijo. Esto solo ocurre en la obra derivada. La única referencia, en todo el drama, a un personaje infantil, alude a la época en que Torcuato era un niño cuya mayor desgracia era no saber a quién debía la vida, como fruto desdichado de un amor ilegítimo (IV.iii). La presencia del niño en los grabados, según creemos, es una estrategia retórica de don Manuel del Socorro Rodríguez, supuesto autor de la obra derivada, tal vez con el propósito de incluir en el elenco a los hijos de don Antonio Nariño y de doña Magdalena Ortega.

La obra derivada dice que el veredicto de la pena de muerte a la que Torcuato había sido condenado, tardó seis años. Ello explica por qué los actores infantiles sean Antonio Nariño y Ortega (de seis meses, nacido el 31 julio de 1791) y Gregorio Nariño y Ortega (de seis años, nacido el 12 de marzo de 1786).

De ser cierta la hipótesis de Santos Molano, de que la mujer expectante que aparece en los dos grabados es doña Magdalena Ortega, quedaría resuelta la polémica sobre «el enigma del Medallón» que planteara la historiadora Carmen Ortega Ricaurte, ${ }^{6}$ el 29 de agosto de 1995 en el Museo El Chicó, donde leyó su ponencia al ser elegida miembro de número de la Sociedad Nariñista, la cual suscitó una acalorada polémica entre la autora y sus contradictores. Los resultados de su investigación se publicaron más tarde (2000), afirmando que las hijas de doña Magdalena Ortega no lo eran de Nariño y que le había sido infiel con Jorge Tadeo Lozano, hijo del marqués de San Jorge. Sin embargo, sus argumentos han sido rebatidos por Osorio (2001) y el Boletín de Historia y Antigüedades 
de 1995 (vol. 82, № 791) plantea el estado de la cuestión. Allí Felipe Osorio Racines, descendiente de Nariño por partida doble, ${ }^{7}$ plantea un interrogante crucial: «¿Aparece antiguo cuadro de la señora de don Jorge Tadeo Lozano?» (pp. 989-996 - medallón).

Carmen Ortega (2000) fundó su investigación en un error incurrido por Hernández y Restrepo (1983), quienes, en la figura 24 de su libro, atribuyen a Magdalena Ortega y Mesa, esposa de Nariño, la identidad de una dama del siglo XVIII representada en el cuadro que se encuentra en la Casa Museo 20 de Julio. Una réplica se colocó en la habitación del Precursor en la Casa Museo de Villa de Leyva, pero gracias a esta investigación, fue reemplazada por la Magdalena Ortega (fig. 15, con el aval de Enrique Santos Molano.

Figura 15. Magdalena Ortega de Nariño, en función teatral, pintada por Joaquín Gutiérrez, c. 1791. Ampliación de su efigie que aparece en la litografía que se reproduce en la figura 13.

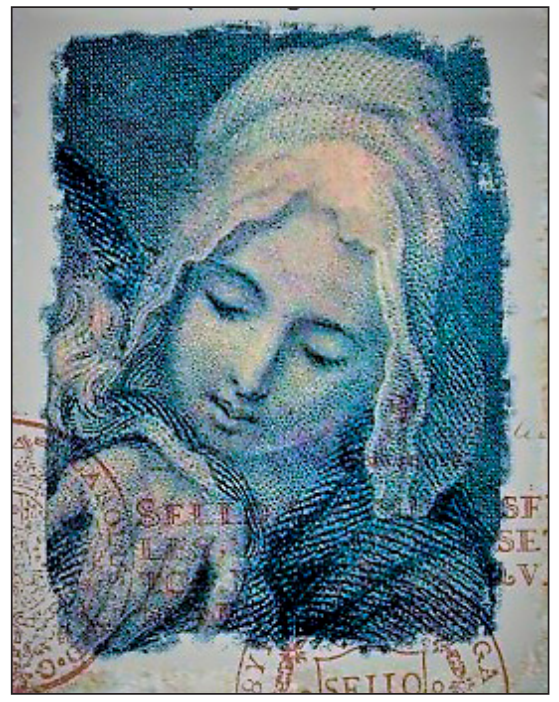

Pero contrario a lo que aducen Hernández y Restrepo de que doña Magdalena se encuentra con uno de sus hijos, y que el medallón que toca el bebé es una miniatura del Precursor, Ortega sostiene que la persona del medallón es Jorge Tadeo Lozano y que Magdalena sostiene una de las hijas que tuvo con Jorge Tadeo, inducida por el desamparo, la soledad, la indigencia, la miseria y el repudio, pues su esposo se encontraba en prisión incomunicado, sin poder recibir a nadie en su celda, lo cual se demostró ser falso.

La imagen de Eugenia, representada por doña Magdalena Ortega de Nariño, puede desvanecer toda

pretensión de su supuesta infidelidad. Los grabados podrían ser una fuente primaria de donde se podría deducir cómo era el verdadero rostro de la esposa de Nariño, a partir de las asociaciones expuestas en este artículo y otras que se puedan inferir.

7 La madre de Felipe Osorio era descendiente legítima, por línea directa, de doña Magdalena Ortega, y su padre, era descendiente, también por línea directa, de Antonia Ricaurte Nariño de Osorio, hija de María Dolores Nariño y Álvarez viuda de Ricaurte, hermana del Precursor-Libertador. 


\section{4}

Doña Magdalena tiene la misma fisonomía y actitud de expectación de la mujer que aparece en los cuadros "La Virgen y el Niño" (fig. 16), y "Familia Sagrada con San Juan Bautista y San Agustín" (fig. 17), que se conservan en el Museo de Arte Colonial de Bogotá, atribuidos a Joaquín Gutiérrez, conocido como «el pintor de los virreyes».

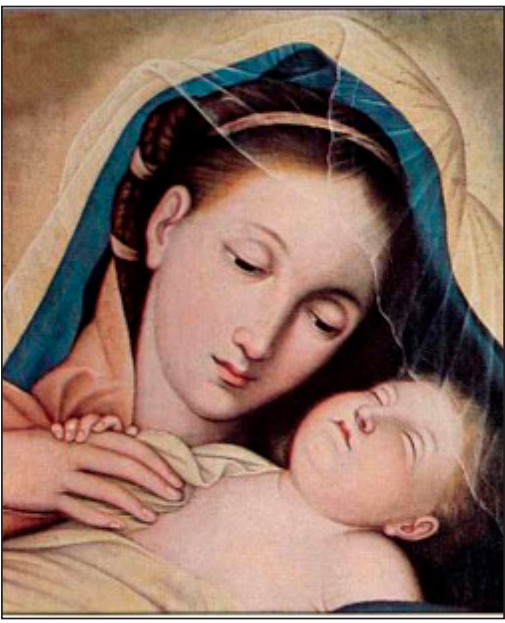

Figura 16. Virgen con el Niño. Óleo sobre lienzo atribuido a Joaquín Gutiérrez (¿1720?1810?). 40×33 cm. Museo de Arte Colonial, Bogotá.

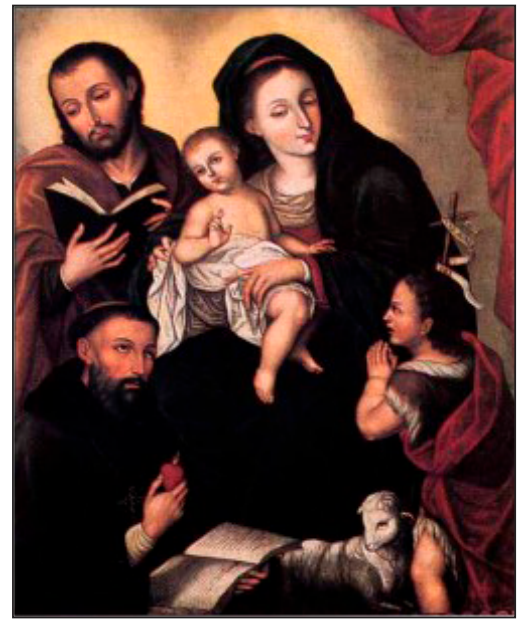

Figura 17. Sagrada Familia con San Juan Bautista y San Agustín. Óleo de Joaquín Gutiérrez. 122x88cm. Museo del Chicó. Sociedad de Mejoras y Ornato, Bogotá.

En el primer grabado (fig. 12) Magdalena Ortega sostiene un niño; en el segundo (fig. 13), observa detrás de la escena, cuando todos se enteran de que el rey ha perdonado a Torcuato, y Laura sale corriendo a abrazar a su esposo. En esos momentos de felicidad extrema, Laura, don Simón y Torcuato se abrazan estrechamente.

\section{Conclusión}

Los dos grabados que aparecen en la versión impresa de 34 páginas de la Defensa del general Nariño, firmado de puño y letra del Precursor (Nariño, 1823a), que se conserva en la Biblioteca Tomás Rueda Vargas, en la Escuela Militar de Cadetes "General José María Córdova", son inéditos hasta ahora y complementan la iconografía actual de Nariño. El maestro Enrique Santos Molano, experto en Nariño, ha certificado su autenticidad.

La dilucidación de los grabados presenta nuevas facetas de la vida de Nariño, como la de representar obras de teatro con sus familiares. En este caso se trata de la tragicomedia El delincuente honrado, de Gaspar 
Melchor de Jovellanos, cuya adaptación fue realizada por Manuel del Socorro Rodríguez.

Ambos cuadros presentan a Nariño en función teatral con su familia: el primero (fig. 11), corresponde al acto II, escena $5^{\text {a }}$ de la obra; Nariño hace el papel de Torcuato, recién casado con Laura, representado por la actriz española Rafaela Isazi, esposa del segundo marqués de San Jorge. Su padre, don Simón, Ilora desconsolado al observar la tragedia de su hija que se despide de su esposo condenado a muerte. Expectante se encuentra Eugenia, doncella de doña Laura, representada por doña Magdalena Ortega de Nariño con su hijo menor en brazos. Este niño es Antonio Nariño y Ortega, nacido en julio de 1791, quien será soldado de la Independencia y apoyo de su padre. El segundo cuadro (fig. 12), que corresponde al acto $\mathrm{V}$, escena $5^{\mathrm{a}}$ de la obra, presenta un desenlace feliz inesperado. El rey perdona a Torcuato, quien abraza a su suegro don Simón, circunspecto por lo inesperado del buen curso que tomaron los hechos. Su esposa Laura no sale de su asombro, y abraza con ternura al padre y al esposo. Entre tanto, la bella Eugenia (Magdalena Ortega) contempla ensimismada a su hijo mayor Gregorio Nariño y Ortega, el primogénito del matrimonio Nariño-Ortega, nacido en marzo de 1786, quien con un tambor entre sus brazos observa a su padre, con mirada impertérrita, tratando de comprender la escena, como en un futuro tratará de comprender por qué su padre es patriota. El padre amará a su hijo realista, pese a no compartir su filiación política.

De ser ciertas las afirmaciones anteriores, quedaría resuelta la polémica sobre el "enigma del medallón". Sería ésta la primera vez en más de 200 años que se presenta la única iconografía certificada que se conoce de doña Magdalena Ortega, quien sirviera de modelo a su amigo Joaquín Gutiérrez, pintor de los virreyes, autor de los cuadros Virgen con el Niño (fig. 16) y la Familia sagrada de San Juan Bautista y San Agustín (fig. 17), en los que la virgen guarda gran parecido con la imagen del personaje Eugenia, representada en las dos litografías. Esto nos hace pensar que el cuadro original del grabado es de Joaquín Gutiérrez. Hasta el momento se encuentra perdido.

\section{Agradecimientos}

El autor desea expresar su más sincero reconocimiento a Héctor José Sarmiento Ramírez, por la rigurosa edición de este artículo; porque lo que pudo mejorarlo, y lo que añadí de mi propia cosecha, no sabría expresarlo. 


\section{Referencias bibliográficas}

1. Allo Maniero, Adita (2015). Prólogo al libro Iconología (2 vols.; t. 1, pp. 7-37) de Cesare Ripa. Madrid: Ediciones Akal / Arte y Estética

2. Gómez Restrepo, Antonio (1926). Bogotá. La literatura colombiana a mediados del siglo XIX. (Dos ensayos). Bogotá: Ediciones Colombia.

3. Hernández de Alba, Guillermo y Restrepo Uribe, Fernando. (1983). Iconografía de Antonio Nariño y recuerdos de su vida. Bogotá: Empresa de Teléfonos de Bogotá.

4. Lamus Obregón, Marina. (2010). Teatro siglo XIX. Compañías nacionales y extranjeras. Medellín: Editores Tragaluz.

5. Nariño, Antonio. (1823a). Defensa del general Nariño (folleto impreso en $8^{\circ}, 34$ p., 16 h. incluye 2 grabados). Copia disponible en la Biblioteca Tomás Rueda Vargas, de la Escuela Militar de Cadetes "General José María Córdova”. Bogotá: Bruno Espinosa de los Monteros, Impresor.

6. Nariño, Antonio. (1823b). Defensa del general Nariño. (folleto impreso en $8^{\circ}, 89$ p., 45 h.). Copia disponible en la Biblioteca Nacional de Colombia. Bogotá: Bruno Espinosa de los Monteros, Impresor.

7. Ortega Ricaurte, José Vicente. (1927). Historia crítica del teatro en Bogotá. Bogotá: Talleres de Ediciones Colombia.

8. Ortega Ricaurte, Carmen. (2000). El enigma del medallón. Polémica histórica sobre la infidelidad de Magdalena Ortega de Nariño. Bogotá: Planeta Colombiana.

9. Osorio Racines, Felipe. (2001). Apología de Magdalena Ortega de Nariño o El fraude del enigma del medallón. Bogotá: Editora Guadalupe.

10. Osorio Racines, Felipe. (2003). Continuación de mi libro "Apología de Magdalena Ortega de Nariño". Bogotá: Editora Guadalupe Ltda.

11. Papel periódico de la Ciudad de Santafé de Bogotá (1791) Noviembre 6: Loa que precedió a la tragedia prosaica intitulada: El delincuente honrado. En Papel periódico de la Ciudad de Santafé de Bogotá, edición facsimilar (1978) t. 2, № 42, viernes 2 de diciembre de 1791, pp. 345-349. Bogotá: Banco de la República.

12. Posada, Eduardo e Ibáñez, Pedro María. (1903). El Precursor. Documentos de la vida pública y privada del General Antonio Nariño. Bogotá: Bibloteca de Historia Nacional.

13. Restrepo Sáenz, José María. (1954). La familia Nariño. Boletín de Historia y Antigüedades, pp. 473-474.

14. Reyes Posada, Carlos José. (2000). Teatro colombiano del siglo XIX. (Prólogo, compilación y notas del autor). Bogotá: Biblioteca Nacional de Colombia. 
15. Santos, Enrique (2013). Antonio Nariño: héroe, libertador, pensador. Bogotá: Biblioteca Colombiana Ilustrada.

16. Suárez, Jesús y Molina, Alejandro. (2019). Defensa del general Nariño ante el Senado en 1823 (Edición crítica). Obra conmemorativa para el Bicentenario. Bogotá: Sello Editorial ESMIC.

17. Suárez, Jesús, Franco, Rafael, Acosta, Ricardo. y Alonso, Hernán. (2017). Nariño el Contador, el Precursor-Libertador: la Ilustración, la Independencia. Tomo 1.1. Bogotá: Sello Editorial ESMIC.

18. Suárez, Jesús, Franco, Rafael, Molina, Alejandro, Acosta, Ricardo y Alonso, Hernán. (2018). Nariño el Contador, el Precursor-Libertador: Defensa de Nariño ante el Senado en 1823 (Edición crítica). Tomo 1.2. Bogotá: Sello Editorial ESMIC.

19. Velandia, Roberto. (1995). Sin fundamento histórico: la acusación contra Magdalena Ortega de Nariño. Boletín de historia y antigüedades № 82 (1791), pp. 985-988.

20. Watson Espener, Maida. y Reyes, Carlos José. (1978). Materiales para una historia del teatro en Colombia. Bogotá: Instituto Colombiano de Cultura.

Para citar este artículo:
Suárez, Jesús Alberto (2019). Más allá del enigma del medallón. Un descubrimiento histórico para reescribir la historia de Magdalena Ortega y Antonio Nariño. Teuken Bidikay Vol. $10 \mathrm{~N}^{\circ}$ 15. Medellín: Politécnico Colombiano. Pp. 59-83 doi:10.33571/teuken.v10n15a2
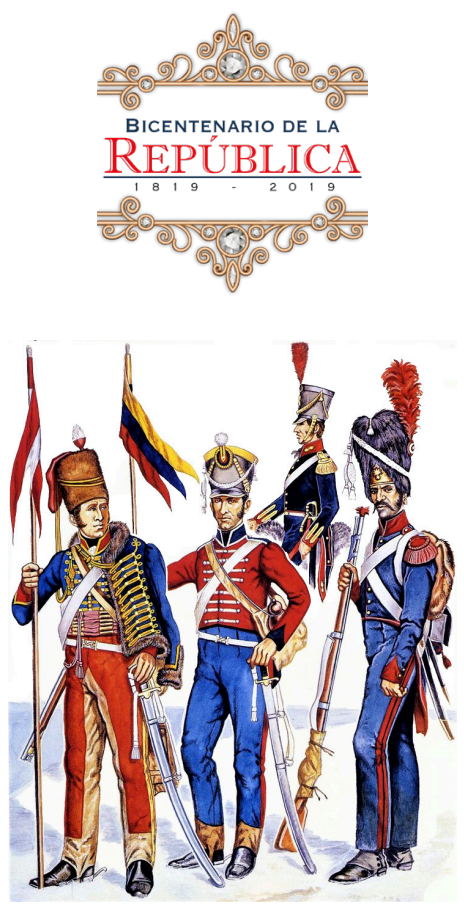
$\begin{array}{llllll}\text { A } & N & E & X & O & 1\end{array}$

\section{Defensa del General Dn ANTONIO NARIÑO Y ÁLVAREZ ante la Cámara del Senado - 1823}

(Sección referida al cargo por malversaciónde fondos de la corona española)

La Tesorería de Diezmos no está en el caso de los demás empleos de administración de rentas. A mí no se me pasaba casa, cajas, faltas ni moneda falsa; no se hacía tanteo cada año, ni nunca; presentaba mi libro de entradas y los libramientos que había pagado, y por uno y otro se veía lo que quedaba en mi poder. Mi obligación, en una palabra, era recibir los enteros, pagar los libramientos y entregar la Tesorería cuando llegara el caso, como lo verifiqué el año de 91. El dinero entraba en mi poder, no en depósito, sino bajo la fianza ilimitada que había dado, para poder negociar con los sobrantes, como lo habían hecho mis antecesores, con menos fianza, y como lo hacía públicamente con conocimiento de todos los interesados, sin que a nadie se le pudiera ocurrir que yo pagara las oficinas, los libros, las faltas de moneda, las cajas, y que diera una fianza ilimitada, solo para percibir 850 pesos, que se consumían en los gastos enunciados. El manejo, pues, de los caudales sobrantes no era un abuso, una falta de confianza, ni un procedimiento que desmintiera mi hombría de bien; y la prueba de este concepto público la voy a demostrar: yo desafío a mis acusadores a que presenten en su favor un documento igual o que se le parezca.

El año de 91, se me manda entregar la Tesorería al Cabildo Eclesiástico: es público y notorio a cuantos existían en esta ciudad en aquel tiempo, que ya tenía las mismas negociaciones de comercio que el año de 94; es igualmente notorio que en aquella época tenía en giro más de cien mil pesos, y que a los veinte días de habérseme mandado entregar rendí mis cuentas y entregué el dinero. Yo llamo aquí la atención del Senado y del público ¿¿Cuánta sería mi reputación de hombría de bien cuando no solo encuentro en veinte días modo de cubrir la caja, sin alterar ni tocar mis negociaciones, sino fiadores que después de esto respondan por mí de más de trescientos mil pesos?? Reflexionad, señores, qué número de personas, todas pudientes, se necesitan en una ciudad como la nuestra para llenar estas dos partidas en tan corto tiempo: los unos me auxiliaban con su dinero, los otros con sus fincas, para ofrecer y dar una fianza de que no ha habido ejemplo. Y en el día ¡Dios justo, Dios eterno!, me veo tratado por esta misma causa [...] pero no es tiempo de distraer vuestra atención del asunto principal.

Toda la ciudad se reunió a mi favor, y contra la prevención y sentimiento del Venerable Deán y Cabildo vuelvo a ser nombrado tesorero por el mismo 
Cabildo. Pasan tres años, sin que en todo este tiempo se oyera una reclamación de ninguno de mis fiadores, a pesar de que todos sabían mis negociaciones. Llega el día funesto de mi prisión no por este motivo, como han dicho mis calumniadores, sino por haber publicado los sacrosantos Derechos del Hombre; y arrastrado a un encierro se apodera el juez de mis papeles, y se me forma un alcance sin intervención mía, a pesar de las disposiciones legales que previenen lo contrario. (Léase el documento número 9.7) Dos meses se pasaron sin que el reverendísimo Arzobispo y Venerable Cabildo pensaran en proveer el empleo, porque estando asegurados sus caudales, y no habiendo dado motivo para que se me despojara de él, solo mi causa podía obligarlos a dar este paso. Así se verificó, y convencidos ya de que debía continuar arrestado, se trató de nombrar tesorero, y por de contado de entregar la cantidad que por las cuentas del contador resultaba contra mí. Si yo me hubiera hallado en el caso del año de 91, todo se habría concluido como se concluyó entonces, pero las circunstancias eran muy diversas; el aspecto de un criminal en causa de Estado mudó toda la escena en mi contra: era preciso hablar y obrar en contra mía, o hacerse sospechoso para con el Gobierno y la Real Audiencia; no había medio, los momentos eran críticos, y el partido que se había de elegir, fácil de adivinar; me quedé solo con un corto número de parientes y amigos, que arrostraron el peligro, y el resto me declaró la guerra.

Se formó el concurso a mis bienes, y todo habría quedado concluido en muy poco tiempo, si la naturaleza de mi causa no lo hubiera impedido. Me hallaba encerrado, no podía por mí mismo dar un paso en el asunto, no sabía otra cosa que lo que el juez me traía a la prisión para que firmara, cuando mi cabeza estaba ocupada solo en pensar cómo la salvaría. Mis fiadores, después de muchos meses de contestaciones inútiles, insignificantes y perjudiciales a sus intereses y a los míos, se vieron precisados a pagar, pero se les entregaron mis bienes; nombraron ellos mismos administradores, y hasta hoy ignoro el resultado de esta administración, ni lo que los bienes embargados produjeron. (Documentos números 7 y 12).

Los señores Gómez y Azuero no deben ignorar la enorme diferencia que hay entre una quiebra fraudulenta y un descubierto que hubiera sido momentáneo sin las circunstancias que lo acompañaron. ¿Será fallido un negociante que, teniendo arreglado su comercio a crédito, se le prende intempestivamente, se le embargan sus bienes, se almacenan y dejan podrir sus frutos, perder sus deudas y disipar su caudal? Hasta hoy, señores, hay bienes míos almacenados, hasta hoy, después de 29 años, hay deudas cobrables sin cobrar, hasta hoy hay cantidades en depósito sin pedirse. ¿Y seré yo culpable de que lloren estas familias que se hicieron cargo de estos bienes, de estas deudas y de estos depósitos, cuando a mí no me ha sido permitido hacerlo? ¿Sería justo que aun cuando yo hubiera adquirido nuevos fondos, los hubiera pagado, 
sin que me dieran cuentas, o me entregaran lo que se me había embargado? Pues con cuánta menos razón se me debe hacer cargo, cuando siempre me he visto imposibilitado de hacerlo, porque padeciendo, o mandando, siempre he estado ocupado en servicio de la patria: de esta patria contra la que hoy también se me acusa de haber sido traidor.

La exposición que aparece en el acta que se acaba de leer es una equivocación nacida del transcurso de los años que han pasado desde aquel tiempo hasta el día. La fianza que di, como se ve por la certificación del escribano público, documento número 2, no solo fue de 80.000 pesos sino ilimitada; y constando por el documento número 11, que en el año de 98 se dio carta de lasto a mis fiadores, mal podía deberse cantidad alguna a Diezmos hasta la época de la revolución. Los bienes embargados subían a 126.000 pesos, y el alcance formado sin intervención mía, porque estaba en un encierro, solo llegó a 81.264 pesos, 6 reales, 7 y cuarto maravedís. Tanto el Venerable Cabildo como mis adores se disputaron la posesión de éstos, y si los fiadores vinieron al fin a lastar, fue por culpa suya, porque no solo se les propusieron, por el Arzobispo y Venerable Cabildo, moratorias para que fueran pagando con el producto de mis bienes embargados, sino que se conformaban con éstos para cubrir la caja; y los fiadores resistieron lo uno y lo otro, como se ve en los documentos 4 y 6 ya citados.

Al tiempo de mi prisión había en Cúcuta, en poder de don Pedro Chauveau, entre otras partidas, la de 300 cargas de cacao, compradas a 21 pesos, con un año de anticipación, para remitirlas a Veracruz, y que se vendieron en Cúcuta mismo a 36 pesos 4 reales. La cuenta con Chauveau subía a más de 15.000 pesos. En Cartagena había 5.555 arrobas de azúcar para remitir a España, cuyo principal y costos hasta aquella plaza subía a 10.164 pesos, 2 y cuarto reales. En La Habana, en poder de don Manuel Quintanilla, había 80 churlas, con 9.925 libras netas de quina, que se estaban vendiendo desde 12 hasta 13 reales libra. Las primeras 15 churlas vendidas antes de mi prisión produjeron 2.785 pesos, como se ve por el documento número 10, que pido se lea... A esta proporción, las 80 churlas hubieran producido 14.863 pesos, si no se hubiera interrumpido su venta; sin contar el mayor precio de las que se remitieron a Veracruz, de cuatro reales más en libra a que se vendieron. En Cádiz, en poder de don Manuel Cortés Díaz, había 166 churlas, con peso neto de 26.282 libras de quina; y en esta ciudad, además de mi casa adornada, de las joyas y alhajas de mi mujer, de mi librería, avaluada en más de 3.000 pesos, se me debían, en sujetos abonados, 41.447 pesos 5 y cuartillo reales. En las moratorias que el reverendo Arzobispo y su Venerable Cabildo propusieron a los fiadores, la mayor cantidad que se les pidió de contado era de 16.000 pesos, y lo demás a irlo pagando por meses de a 1.000, 2.000 y 3.000 pesos, según iban corriendo los años. Vistas las partidas de arriba, ¿quedará duda de que hubieran podido cumplir con las moratorias, sin poner un real de 
su bolsillo? Y si fue culpa suya y no mía el no haberlas admitido, ¿̇eré yo el responsable, el culpado, en que después se les haya obligado a hacer el lasto? ¿Se me podrá dar el honroso título de fallido, porque teniendo en su poder los fiadores mis bienes, los han dejado perder? Yo he pedido muchas veces esta cuenta, yo me he presentado a la Real Audiencia demandando a los fiadores para que me la den y paguen el sobrante que debió resultar a mi favor, y ni aun pude conseguir que se pagara la dote de mi mujer, graduada con preferencia a los mismos fiadores. ¿Qué extraño es, pues, que haya otras deudas, como la dote de mi mujer, sin pagarse, si los fiadores no han querido rendir las cuentas? ¿Sería indiferente para mí el que se pagara o no la dote que debía entrar en mi bolsillo? Esta es una prueba clara, indubitable, de que me ha sido imposible vencer la resistencia que se ha opuesto constantemente a la liquidación de esta ruidosa cuenta.

Queda, pues, demostrado que el año de 1791 entregué la Tesorería de Diezmos al Venerable Deán y Cabildo por disposición del Rey, y que en el manejo de 482.351 pesos, o cerca de medio millón de pesos, no me resultó ni un solo real de alcance, porque pude por mí mismo formar mis cuentas y entregar el empleo.

Queda igualmente demostrado que en el año de 94, aunque por la cuenta del contador de diezmos, formada sin intervención mía, resultó un alcance de 81.000 y más pesos, se me embargaron bienes que no solo cubrían esta cantidad, sino que me quedaba un sobrante de muchos miles.

Tercero: que habiéndose los fiadores hecho cargo no solo de los bienes suficientes para cubrir el alcance de la cuenta, sino del total, que subía a más de 126.000 pesos, aunque lastaran al principio la fianza, por el mal modo con que se manejó el asunto, ellos, y no yo, son los responsables a la cantidad sobrante, para cubrir la dote de mi mujer y alguna otra pequeña deuda que resulte de mis negociaciones.

Cuarto: que siendo mis fiadores responsables a todos los acreedores que se presentaron al concurso de estos bienes, por haber cantidad suficiente con qué pagarlos, no habiendo dado cuenta de su producto, y no debiendo yo en el día ni a particulares, ni al Tesoro Público, ni a la Mesa Capitular de Diezmos, el epíteto de fallido que se me da es un [insulto, una calumnia de Diego Gómez inventada para sus fines particulares]. Que se lean las certificaciones de los ministros del Tesoro Público y del notario y contador de diezmos.

Vosotros lo acabáis de oír, señores, con documentos incontestables: no solo no soy deudor al Tesoro Público, a los diezmos ni a los fiadores de la Tesorería, sino que éstos me son responsables del sobrante de mis bienes, después de cubierto el concurso que a ellos se formó, por efecto de la prisión 
que sufrí, por haber publicado los Derechos del Hombre.

Fijad ahora, ilustres senadores, vuestros ojos [sobre el acusado y los acusadores] bajadlos por un momento y comparad [Diatriba inédita contra Diego Gómez y Vicente Azuero]. Comparad, vuelvo a decir, [las rapiñas de estos dos hombres] con los sacrificios pecuniarios que por mis cuentas y negociaciones se ve que he sufrido por amor a la causa de la libertad. Aquí veis [...] y allá me veis sacrificando por la patria unas negociaciones que en menos de diez años me habrían hecho un hombre millonario. En solo Cádiz, Veracruz y La Habana, tenía 326 churlas de quina que, como se ha visto por la cuenta del documento número 10 , solo 15 churlas que se habían vendido antes de mi prisión produjeron 2.785 pesos, a cuya proporción las 326 churlas dan 58.680 pesos; y computando las que había en camino en esta ciudad, y en contratas que aún no se han acabado de satisfacer, que pasaban de 600 churlas, al mismo precio, subía su importe a 108.000 pesos que por la mayor parte se han dejado perder. La negociación de cacaos, como se ve por la última cuenta que corre en los autos de don Pedro Chauveau, aún sin remitir a Veracruz, se vendieron en Cúcuta mismo a 36 pesos, cuando solo habían costado, el año antes, 21 pesos. ¿Y qué diremos de la negociación de azúcares comenzada al tiempo que se acababa de perder la Isla de Santo Domingo, con la revolución de los negros, y de donde salían todos los años dos millones de cajas? Aquí llegué a comprar la arroba al mismo precio que se llegó a vender la libra en Europa. No hablo de otras negociaciones tan bien calculadas como estas porque esto basta para que se conozca, hasta por los más alucinados, si seré un fallido fraudulento, [como Azuero, que se come los diezmos para figurar] o un hombre que ha sacrificado una fortuna brillante, por amor a la libertad.

Suponed, señores, que en lugar de haber establecido una imprenta a mi costa, en lugar de haber impreso los Derechos del Hombre, en lugar de haber acopiado una exquisita librería de muchos miles de libros escogidos, en lugar de haber propagado las ideas de libertad, hasta en los escritos de mi defensa, como se verá después, solo hubiera pensado en mi fortuna particular, en adular a los virreyes, con quienes tenía amistad, y en hacer la corte a los oidores, como mis enemigos se la han hecho a los expedicionarios. ¿Cuál habría sido mi caudal en los 16 años que transcurrieron hasta la revolución? ¿Cuál habría sido hasta el día?... ¿YY porque todo lo he sacrificado por amor a la patria, se me acusa hoy, se me insulta, con estos mismos sacrificios, se me hace un crimen de haber dado lugar con la publicación de los Derechos del Hombre, a que se confiscaran mis bienes, se hiciera pagar a mis fiadores, se arruinara mi fortuna y se dejara en la mendicidad a mi familia, a mis tiernos hijos? En toda otra república [...] se habría propuesto, en lugar de una acusación, que se pagaran mis deudas del Tesoro Público, vista la causa que los había ocasionado, y los 29 años que después habían transcurrido. 
Dudar, señores, que mis sacrificios han sido por amor a la patria es dudar del testimonio de vuestros propios ojos. ¿Hay entre las personas que hoy me escuchan, hay en esta ciudad y en toda la República, una sola que ignore los sucesos de estos 29 años? ¿Hay quien no sepa que la mayor parte de ellos los he pasado encerrado en el Cuartel de Caballería de esta ciudad, en el de Milicias de Santa Marta, en el del Fijo de Cartagena, en las Bóvedas de Bocachica, en el Castillo del Príncipe de La Habana, en Pasto, en el Callao de Lima, y últimamente en los calabozos de la cárcel de Cádiz? ¿Hay quien no sepa que he sido conducido dos veces en partida de registro a España, y otra hasta Cartagena? Todos lo saben; pero no saben, ni pueden saber, los sufrimientos, las hambres, las desnudeces, las miserias que he padecido en estos lugares de horror, por una larga serie de años. Que se levanten hoy del sepulcro Miranda, Montúfar, el virtuoso Ordóñez, y digan si pudieron resistir a solo una parte de lo que yo por tantos años he sufrido; que los vivos y los muertos os digan si en toda la República hay otro que os pueda presentar una cadena de trabajos tan continuados, y tan largos, como los que yo he padecido por la patria, por esta patria por la que hoy mismo se me está haciendo padecer. Sí, señores, hoy estamos dando al mundo el escandaloso espectáculo de un juicio al que no se atrevió el mismo gobierno español. Él ha dicho en términos claros que se retenga el sobrante de mis bienes, después de pagado el alcance, a disposición de la Real Audiencia; él ha creído que había un sobrante, y por lo mismo nunca me juzgó fallido.

Bogotá, 14 de mayo de 1823.
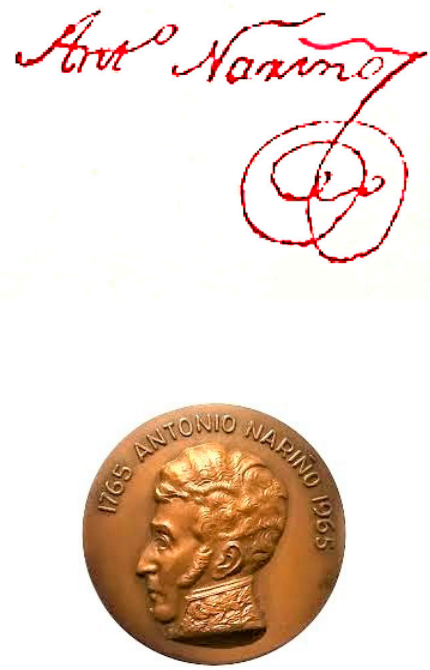

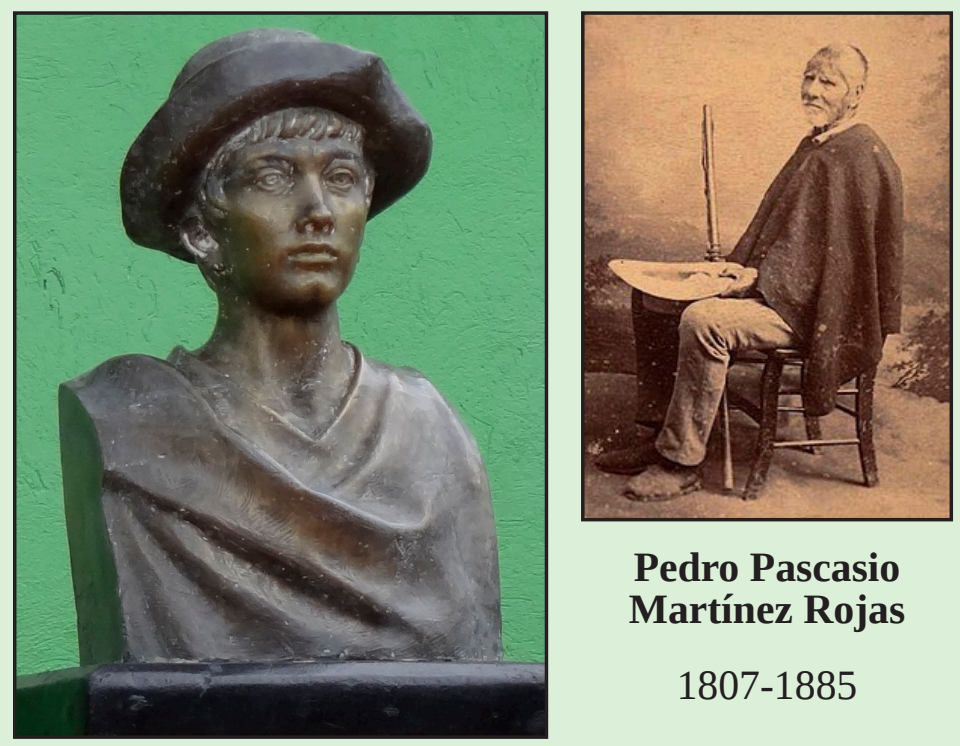

\section{Pedro Pascasio Martínez Rojas}

\section{7-1885}

Ejemplo de disciplina militar, niño héroe de la Independencia, soldado destacado de la patria y símbolo de honestidad, son algunos de los apelativos con los que se identifica a este niño campesino que con solo 12 años, se cubrió de honores en la Batalla de Boyacá, que selló la independencia de Colombia. Luego de la derrota y desbandada de las tropas realistas, Pedro capturó al comandante del ejército español, Coronel José María Barreiro, quien le ofreció un saco de monedas a cambio de su libertad. A pesar de su corta edad, de su extrema pobreza y de la natural aversión al enemigo, el niño le perdonó la vida al español, rechazó su oferta y lo entregó como prisionero a Bolívar. Su actuación lo hizo merecedor del ascenso al grado de Sargento y recibió una gratificación de cien pesos. En 1885 se fue al cielo de los héroes y en honor a su legado de honestidad, se creó la medalla "Pedro Pascasio Martínez de Ética Republicana", que enaltece a quienes trabajan en la recuperación de los valores éticos ciudadanos.

Lina Vergara V. Politécnico Colombiano. 